
\title{
R Reserach S Suare \\ Outcomes of Ahmed Glaucoma Valv Implantation in Patients with Pars Plana Vitrectomy History
}

\section{Sevgi Subasi ( $\nabla$ sevgiozel_5@hotmail.com )}

Kocaeli Universitesi Tip Fakultesi

\section{Nursen Yuksel}

Kocaeli Üniversitesi Tıp Fakültesi: Kocaeli Universitesi Tip Fakultesi

\section{Levent Veysel Karabas}

Kocaeli Üniversitesi: Kocaeli Universitesi

\section{Busra Yilmaz Tugan}

Kocaeli University: Kocaeli Universitesi

\section{Ece Basaran}

Kocaeli Üniversitesi: Kocaeli Universitesi

\section{Research Article}

Keywords: Ahmed glaucoma valv, neovascular glaucoma, pars plana vitrectomy, secondary glaucoma.

Posted Date: April 5th, 2021

DOI: https://doi.org/10.21203/rs.3.rs-392898/v1

License: (c) (1) This work is licensed under a Creative Commons Attribution 4.0 International License. Read Full License 


\section{Abstract}

Background and Objective: Ahmed glaucoma valv (AGV) implantation is one of the successful surgical methods in secondary glaucoma that develops after pars plana vitrectomy (PPV). In our study, we aimed to evaluate the 1-year results of AGV implantation in patients with a history of PPV.

Study Design: A total of 26 patients who underwent AGV implantation after PPV were included in our retrospective study. Fourteen of 26 patients had AGV implantation due to neovascular glaucoma (NVG) and 12 of them had secondary refractory galucoma. Data of these two groups of patients were evaluated in terms of IOP reduction, number of medication use, surgical complete and qualified success, surgical failure, and complications.

Results: The mean IOP was $29.54 \pm 4.87 \mathrm{mmHg}$ at the preoperative of AGV implantation and $12.88 \pm 4.17$ at the twelfth month visit in overal group. There was no statistically significant difference between two groups in terms of IOP in preoperative and all postoperative visits $(p>0.05)$. The mean intervals between PPV and AGV implantation were $67 \pm 34$ days in NVG and $391 \pm 500$ days in non-NVG group $(p=0.017)$. In overal group, $91.7 \%$ of patients had improvement in BCVA at the twelfth month visit. Complete and qualified surgical success rates were $75 \%, 83.3 \%$ in NVG group and $50 \%, 91.7 \%$ in non-NVG group respectively. There was no devastating complication in both group.

Conclusion: AGV implantation is a safe and effective surgical method in uncontrolled IOP elevations after PPV. While surgical success and failure rates was similar between etiologies, the time required for AGV implantation after PPV was shorter in NVG etiology.

\section{Introduction}

Retinal surgery has been improved a lot with the introduction of closed system vitrectomy in the 70's [1]. As time goes by, the indications for vitrectomy increased considerably [2]. Complications that developed with increasing number of postoperative patients started to be investigated and one of the most important of these is glaucoma [3]. Intraocular pressure (IOP) values higher than $30 \mathrm{mmHg}$ were detected in $35 \%$ of patients who received pars plana vitrectomy (PPV) [4]. It has been reported that the increase in IOP develops depending on the surgery and the tampon used, responds well to antiglaucoma treatment and is generally temporary [5]. Increased IOP after PPV which cannot be reduced with medical treatment, may require surgery. In these refractory glaucoma cases, especially glaucoma drainage implants are recommended. Krupin-Denver, Joseph, Molteno, Baerveldt and Ahmed glaucoma valve (AGV) have been used as glaucoma devices. The AGV is easy to place and works only when IOP is above $8 \mathrm{mmHg}$, prevents low IOP [6-8].

Neovascular glaucoma (NVG) is one of the common complications of PPV applied for proliferative diabetic retinopathy [9]. Medical therapy alone is insufficient to control increased IOP in patients with $N V G$, usually surgical intervention is required. However, traditional filtration surgery shows a poor 
prognosis due to increased fibrovascular proliferation or bleeding [10]. AGV implantation is one of the best options for uncontrolled IOP increases after PPV in patients with NVG.

We know that AGV implantation is successful surgical method in reducing IOP in a controlled manner [11]. But there is insufficient data on its results in patients who had undergone PPV. The aim of our study is to clarify the effectiveness, reliability, and surgical success factors of AGV implantation in patients who had undergone PPV for different etiologies and also to compare the effect of etiology on outcomes.

\section{Material And Method}

\section{Patients}

We retrospectively analyzed the medical records of 26 patients who were treated with AGV implantation due to secondary glaucoma following PPV between 2012 and 2018 by the same surgeon at the $* \star \star \star *$

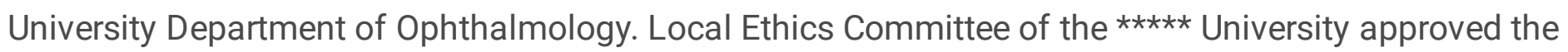
study and also the study adhered to the tenets of the Declaration of Helsinki.

Indications for PPV are as follows: vitreous hemorrhage due to central retinal vein occlusion, diabetic retinopathy or tractional retinal detachment, rhegmatogenous retinal detachment, drop intraocular lens and endopthalmitis. Despite the maximum tolerable medical treatment after PPV, IOP remained high in all patients and therefore the need for surgery occurred. All AGV implantation surgeries were performed by the same surgeon (NY) and AGV-FP7 model was used in all of them. Twenty-four of the 26 patients completed the 12 months follow-up, while 2 patients died after the 6 months follow-up. Patients with primary open-angle glaucoma before PPV and no light perception before AGV implantation were excluded from the study. Neovascular glaucoma was diagnosed as an IOP increase despite maximum medication use accompanied by neovascularization of the iris and/or anterior chamber angle. Patients with a history of PPV who had AGV implantation due to NVG and other than neovascular glaucoma (non-NVG) were evaluated and compared as two separate groups simultaneously.

The ophthalmologic examination results were obtained from the patients' records, the data included in the evaluation were: best corrected visual acuity (BCVA), biomicroscopy, gonioscopy, fundus examination, IOP measurement value with Goldmann applanation tonometry and the number of glaucoma medication used. The time interval between PPV and AGV implantation were recorded. Patients' findings at 3, 6 and 12 months after AGV implantation including; change of BCVA (improvement or maintenance within 1 Snellen line or decrease more than one line), IOP, number of glaucoma medications, and complications were evaluated. All patients with increased IOP after AGV implantation were treated medically, and none of them required additional surgery.

Complete success of AGV implantation was defined as follows: an IOP of 5 to $18 \mathrm{mmHg}$ and a decrease in IOP of $\geq 20 \%$ from baseline IOP without medications and further glaucoma surgery. Qualified success was defined as follows: an IOP of 5 to $18 \mathrm{mmHg}$ and a decrease in IOP of $\geq 20 \%$ from baseline IOP with or without glaucoma medications. Failure was defined as IOP higher than $18 \mathrm{~mm} \mathrm{Hg}$ on maximally 
tolerated medical therapy, loss of light perception due to glaucomatous optic neuropathy, requirement of additional glaucoma surgery, development of the devastating complications [12]. To estimate failure rates, survival analysis was performed using recorded data.

\section{Surgical procedures}

All patients underwent standard PPV with three 23-gauge sclerotomies, additional procedures (posterior chamber lens implantation, endophotocoagulation, phacoemulsification) were applied if necessary. In patients with regmatogenous retinal detachment, $\mathrm{SO}$ or C3F8 gas were used as a tamponade to ensure retinal reattachment. SO was removed after the resolution of the retinal detachment or when the IOP increased because of the pupillary block. Silicone oil was taken before AGV implantation in all patients. An additional vitrectomy was performed when retinal detachment or vitreous hemorrhage developed.

AGV implantation was performed using the fornix-based conjunctival blebs into the upper temporal quadrant between the superior rectus and the lateral rectus muscles. A half scleral thickness $4 \times 4 \mathrm{~mm}$ wide scleral flap was created. The device was sutured to the sclera with $10-0$ nylon sutures approximately 8 to $9 \mathrm{~mm}$ behind the limbus. The anterior chamber was accessed with a 23-gauge needle under the scleral flap, then the tube placed into the anterior chamber through the needle track. The scleral flap was sutured with $10-0$ nylon sutures and conjunctiva were closed with $8-0$ vicryl sutures.

\section{Statistical analysis}

All statistical analyses were performed using IBM SPSS for Windows version 20.0 (SPSS, Chicago, IL, USA). Shapiro-Wilk's test was used to assess the assumption of normality. Continuous variables were presented depending on normal distribution with either mean \pm standard deviation or (in case of no normal distribution) median (25th-75th percentile). Categorical variables were summarized as counts (percentages). Comparisons of continuous variables between groups were carried out using independent samples t test/Mann-Whitney $U$ test, whichever was appropriate. The changes in variables between time periods were analyzed by paired samples $t$ test/related samples Wilcoxon signed rank test and Friedman's two-way analysis of variance. Association between two categorical variables was examined by Chi-square test. Kaplan-Meier method with Log Rank test was used for survival analysis. All statistical analyses were carried out with $5 \%$ significance and a two-sided $p$-value $<0.05$ was considered as statistically significant.

\section{Results}

Twenty-six eyes of 26 patients were included in our retrospective study. There were $6(23.1 \%)$ female and $20(76.9 \%)$ male patients. The mean age of the patients was $60.85 \pm 14.35$ years. Fourteen eyes had NVG (53.8\%) and 12 eyes had non-NVG ( $46.2 \%)$.

Baseline parameters including; age, indication of PPV, tamponade of post-PPV, preoperative IOP values, interval between PPV and AGV implantation and follow-up time were shown in Table 1. There was no complication in 20 patients (76.9\%). The complications that occured were hyphema in three eyes, early 
hypotonia in four eyes, device exposure in one eye, shallow anterior chamber in one eye and choroid detachment in one eye. The most of the complications were improved with medical intervention but for device exposure, surgical intervention required. There was no statistically significant difference between NVG and non-NVG groups in terms of patients implanted with tamponade after PPV $(p=0.084)$. The interval between vitrectomy and AGV implantation was $216 \pm 574$ days in overal group. There was statistically significant difference between NVG group ( $67 \pm 34$ days) and non-NVG group (391 \pm 500 days) in terms of interval $(p=0.017)$.

The mean pre-AGV IOP and the mean preoperative number of medications were similar between NVG and non-NVG groups ( $p=0.193, p=0.494$, respectively). There were no statistically significant difference between NVG and non-NVG groups in terms of mean IOP and mean number of medications use at 6 and 12 months (Table 2, Figure 1). There was statistically significant decrease of repeated measures of IOP (between pre-AGV and post-AGV visits) both NVG and non-NVG groups ( $<<0.001, p<0.001$, respectively). The number of medication use was shown statististically significant decrease after AGV implantation in all groups. Nevertheless, Also BCVA values and change of BCVA were shown in Table 3.

The surgical complete and qualified success rates of overal patients were 18/26 (69.2\%), 25/26 (96.2\%) in 6 months and 15/24 (62.5\%), 21/24 (87.5\%) in 12 months, respectively. The surgical failure rate of overal patients were $1 / 26(3.8 \%)$ and 3/24 (12.5\%) in 6 and 12 months respectively. The distribution of surgical success and failure rates according to groups were shown in Table 4. Kaplan Meier survival analysis showed that there was no statisticaly significant difference in surgical failure between NVG and non-NVG groups (Figure 2, $p=0.581$, Kaplan-Meier survival analysis with Mantel-Cox Log Rank test).

\section{Discussion}

Secondary glaucoma is one of the common complications which is caused by many reasons seen after vitreoretinal surgery. Some of the reasons reported in the literature are: increased oxidative load in vitreous cavity causing trabecular damage after vitrectomy, trabecular scars due to small lesions created during vitrectomy, progress of neovascularization, use of silicone oil in vitreoretinal surgery [13-16]. In several studies, increased IOP in the late period after vitreoretinal surgery has been reported as $26-41 \%$ $[17,18]$. Glaucoma devices come to the fore because the success rates of traditional methods are low in such conditions when medical treatment's lowering IOP effect is insufficient both of these conditions. AGV is one of the most used glaucoma devices and its success has been reported in such cases [19,20]. Neovascular glaucoma is another entity where AGV implantation is one of the most important surgical options in resistant IOP increases after vitrectomy. Vitrectomy is the main treatment for complications such as vitreous hemorrhage, tractional retinal detachment which secondary to proliferative diabetic retinopathy, and retinal vein occlusion. However, after vitrectomy eyes usually results in progression of anterior segment neovascularization and NVG. The incidence of postoperative NVG in such patients has been reported between $2 \%$ and $18 \%[16,21]$. In these conditions AGV implantation is one of the most recommended surgical methods. 
The time until the requirement for AGV implantation after vitrectomy has been mentioned in some of the past studies. In a NVG study, the time between PPV and NVG development was reported as 151 days and it was emphasized that surgery was required in $56 \%$ of these patients [16]. In another one the interval between PPV and AGV implantation was reported as $7.5 \pm 2.2$ months [22]. Furthermore, in our study, the mean interval between PPV and AGV implantation was $1.8 \pm 2.3$ months ( $67 \pm 34$ days). We attribute the short time between AGV implantation and PPV to the fact that the NVG development process started before vitrectomy and the IOP control during vitrectomy was due to medical treatment. The progression of neovascularization after vitrectomy resulted in deterioration of drug control in a short time. Besides that the mean intervals between PPV and AGV implantation were $12.41 \pm 16.2$ months and the mean interval between PPV and secondary refractory glaucoma formation was $391 \pm 500$ days in our non-NVG group. According to our results, the development time of the secondary glucoma that will require AGV implantation in vitrectomized eyes varies depending on the etiology (NVG or non-NVG). Patients who are followed up for reasons such as proliferative diabetic retinopathy and vein occlusion, who are likely to develop NVG, should be followed up more closely in terms of IOP after PPV. The requirement for surgery in terms of IOP develops earlier in such patients.

When the literature is examined, the place of AGV implantation in the NVG and secondary glaucoma that develops in vitrectomized eyes is becoming more and more solid. Although there are various success rates in the literature, there are not enough data comparing the success rates between NVG and non-NVG etiology. Park et al reported the cumulative probabilities of success rates as $92.9 \%, 89.9 \%, 74.7 \%$ and 62.5\% after AGV implantation in NVG patients who had vitreoretinal surgery history at 6 months 1,2 and 3 years, respectively [20]. Jo et al reported overal success rate as $80.1 \%$ during a mean follow-up period of 43.6 months in patients who had secondary glaucoma after vitrectomy [23]. 73.1\% and $63.2 \%$ success rates were reported in NVG patients after AGV implantation, at 12 months by Netland and Yalvac et al, respectively $[24,25]$. However, some of these patients were not vitrectomized in these studies. In our study, success rates were evaluated in overal patients and seperately NVG and non-NVG patients. Surgical qualified success rates were $96.2 \%$ and $87.5 \%$ in overal patients at 6 and 12 months, respectively. In terms of surgical success and surgical failure rates, the etiology of patients (NVG and nonNVG) did not cause statistical significant change. Nevertheless, while surgical qualified success rates in the 6th month were similar between the NVG (92.9\%) and non-NVG (100\%) groups, the surgical qualified success rate in the NVG group (83.3\%) at the 12th month decreased similar as the non-NVG group (91.7\%). According to complete success rates NVG group had greater rate (75\%) than non-NVG group (50\%) at 12 months but these difference was not statistically significant. Cumulative probability of success rates were similar between groups in terms of qualified success.

In our study, in accordance with the literature, even if the etiology is NVG, refractory secondary glaucoma after vitrectomy, it was seen that AGV implantation significantly reduces IOP and the amount of medication used. Besides that, in terms of BCVA, $92.6 \%, 91.7 \%$ of overal patients had improvement or maintenance at 6 and 12 months, respectively. There was no devastating complication at any case. The AGV implatation at all groups had safety and efficacy in terms of IOP, BCVA and complications. 
Limitations of our study are small sample size, retrospective design and the lack of control cases. For providing stronger evidence in terms of these conditions, there is need of prospective randomized large sample sized studies with case- control design.

In conclusion, AGV implantation in both patients (NVG and non-NVG etiology) with uncontrolled IOP after vitreoretinal surgery was safe and effective choice. The surgical success and failure rates were similar and the necessity of time of AGV implantation was lesser in NVG etiology.

\section{Declarations}

Authors declare no potential conflict of interest.

\section{References}

1. Machemer R, Parel JM, Buettner H. (1972) A new concept for viterous surgery. Instrumentation. Am J Ophthalmol 73:1-7.

2. Kim HK, Chung HY, Chung YT. (1997) The clinical evaluation of pars plana vitrectomy in various ocular disease. J Korean Ophthalmol Soc 38:2020-7.

3. Jung BY, Shin JP, Kim SY. (2002) Surgical outcome and postoperative complications of vitrectomy for diabetic retinopathy. J Korean Ophthalmo I Soc 43:1635-43.

4. Han DP, Lewis H, Lambrou FH Jr, et al. (1989) Mechanisms of intraocular pressure elevation after pars plana vitrectomy. Ophthalmology 96:1357-62.

5. Q. H. Nguyen, M. A. Lloyd, D. K. Heuer, G. Baerveldt, J. S. Lean, and P. E. Liggett (1992) Incidence and management of glaucoma after intravitreal silicone oil injection for complicated retinal detachments. Ophthalmology 99:1520-1526.

6. I. U. Scott, S. J. Gedde, D. L. Budenz et al., (2000) Baerveldt drainage implants in eyes with a preexisting buckle," Archives of Ophthalmology 118:1509-1513.

7. A. L. Coleman, R. Hill, M. R. Wilson et al. (1995) Initial clinical experience with the Ahmed glaucoma valve implant," American Journal of Ophthalmology 120: 23-31.

8. K. C. Huh and C. W. Kee (2000) A clinical analysis of the Ahmed glaucoma valve implant with or without partial ligation of silicone tube Journal of the Korean Ophthalmological Society 41: 26112617.

9. Diabetic Retinopathy Vitrectomy Study Research Group Early vitrectomy for severe vitreous hemorrhage in diabetic retinopathy. Four-year results of a randomized trial: Diabetic Retinopathy Vitrectomy study report 5. (1990) Arch Ophthalmol 108:958_964.

10. Allen RC, Bellows AR, Hutchinson BT, et al. (1982) Filtration surgery in the treatment of neovascular glaucoma. Ophthalmology 89:1181_1187.

11. J. H. Lee, S. S. Kim, and Y. J. Hong (2001) A clinical study of the Ahmed valve implant in refractory glaucoma," Journal of the Korean Ophthalmological Society 42:1003-1010. 
12. Heuer DK, Barton K, Grehn F, et al (2009) Consensus on definitions of success. Guidelines on design and reporting of glaucoma surgical trials 15 .

13. N. M. Holekamp, Y. B. Shui, and D. Beebe (2005) Vitrectomy surgery increases oxygen exposure to the lens: a possible mechanism for nuclear cataract formation," American Journal of Ophthalmology, 139;2:302-310.

14. S. Chang (2006) LXII Edward Jackson lecture: open angle glaucoma after vitrectomy," American Journal of Ophthalmology 141;6:1033-1043.

15. E. Van Aken, H. Lemij, Y. Vander Haeghen, and P. de Waard (2010) Baerveldt glaucoma implants in the management of refractory glaucoma after vitreous surgery Acta Ophthalmologica 88;1:75-79.

16. A. Goto, M. Inatani, T. Inoue et al. (2013) Frequency and risk factors for neovascular glaucoma after vitrectomy in eyes with proliferative diabetic retinopathy Journal of Glaucoma 22;7:572-576.

17. J. J. Hwang, Y. Y. Kim, and K. Huk (2000) Risk factors of intraocular pressure elevation after pars plana vitrectomy," Journal of the Korean Ophthalmological Society 41:945-950.

18. D. P. Han, H. Lewis, F. H. Lambrou Jr., W. F. Mieler, and A. Hartz (1989) Mechanisms of intraocular pressure elevation after pars plana vitrectomy Ophthalmology 96;9:1357-1362.

19. Hong JW, Choi GJ. (2005) Ahmed valve implantation for refractory glaucoma following pars plana vitrectomy. Korean J Ophthalmol 19:293-296.

20. Park UC, Park KH, Kim DM, Yu HG. (2011) Ahmed glaucoma valve implantation for neovascular glaucoma after vitrectomy for proliferative diabetic retinopathy. J Glaucoma 20:433-438.

21. Kumagai K, Furukawa M, Ogino N, Larson E, Iwaki M, Tachi N. (2009) Long-term follow-up of vitrectomy for diffuse nontractional diabetic macular edema. 29(4):464-472.

22. Cheng Y, Liu XH, Shen X, Zhong YS. (2013) Ahmed valve implantation for neovascular glaucoma after 23gauge vitrectomy in eyes with proliferative diabetic retinopathy. Int $J$ Ophthalmol 18;6(3):316320.

23. Jo J, Sung KR, Kim YJ. (2018) Influence of Vitrectomy-related Factors on the Outcome of Ahmed Glaucoma Valve Implantation. Korean J Ophthalmol 32(5):400-408.

24. Peter A. Netland, MD, PhD, Kyoko Ishida, MD,w and John W. Boyle, MD. (2010) The Ahmed Glaucoma Valve in Patients With and Without Neovascular Glaucoma. J Glaucoma 19:581-586.

25. I S Yalvac , U Eksioglu, B Satana, S Duman (2007) Long-term results of Ahmed glaucoma valve and Molteno implant in neovascular glaucoma. Eye (Lond) 21(1):65-70.

\section{Tables}

Table 1: Baseline characteristics of patients before AGV implantation surgery 


\begin{tabular}{|c|c|c|c|c|}
\hline & $\begin{array}{l}\text { Total } \\
(n=26)\end{array}$ & $\begin{array}{l}\text { NVG } \\
(n=14)\end{array}$ & $\begin{array}{l}\text { Non-NVG } \\
(n=12)\end{array}$ & $\mathrm{p}$ value \\
\hline Age (years) & $\begin{array}{l}60.85 \pm \\
14.35\end{array}$ & $\begin{array}{l}64.29 \pm \\
11.30\end{array}$ & $\begin{array}{l}56.83 \pm \\
16.86\end{array}$ & $p=0.274$ \\
\hline \multicolumn{5}{|l|}{ Indication of vitrectomy } \\
\hline \multicolumn{5}{|l|}{$\begin{array}{l}\text { Proliferative diabetic retinopathy and } \\
\text { central retinal vein oclusion }\end{array}$} \\
\hline \multirow{2}{*}{ Regmatogenous retinal deteachment } & $14(53.8 \%)$ & $14(53.8 \%)$ & & \\
\hline & 8(30.8\%) & & $8(66.7 \%)$ & \\
\hline \multirow{2}{*}{ Endopthalmitis } & $2(7.7 \%)$ & & $2(16.7 \%)$ & \\
\hline & $2(7.7 \%)$ & & $2(16.7 \%)$ & \\
\hline \multicolumn{5}{|l|}{ Tamponade of post-PPV } \\
\hline Silicone oil & $9(34.6 \%)$ & $2(14.3 \%)$ & $7(58.3 \%)$ & \\
\hline C3F8 gas & $4(15.4 \%)$ & $3(21.4 \%)$ & $1(8.3 \%)$ & \\
\hline Fluid & $13(50.0 \%)$ & $9(64.3 \%)$ & $4(33.3 \%)$ & \\
\hline \multicolumn{5}{|l|}{ IOP $(\mathrm{mmHg})$} \\
\hline Before vitrectomy & $19.15 \pm 6.54$ & $20.21 \pm 6.80$ & $17.92 \pm 6.28$ & 0.297 \\
\hline After vitrectomy & $20.50 \pm 7.88$ & $20.50 \pm 8.13$ & $20.50 \pm 7.93$ & 0.940 \\
\hline Before AGV & $29.54 \pm 4.87$ & $28.36 \pm 4.76$ & $30.92 \pm 4.83$ & 0.193 \\
\hline Pre-AGV number of medication & $3.62 \pm 0.85$ & $3.71 \pm 0.82$ & $3.50 \pm 0.90$ & $p=0.494$ \\
\hline \multicolumn{5}{|l|}{ Interval between PPV and AGV } \\
\hline Month & $6.73 \pm 12.16$ & $1.85 \pm 2.31$ & $12.41 \pm 16.26$ & $p=0.020$ \\
\hline Day & $216 \pm 574$ & $67 \pm 34$ & $391 \pm 500$ & $p=0.017$ \\
\hline \multicolumn{5}{|l|}{ Follow-up time after AGV } \\
\hline Month & $30.7 \pm 26.2$ & $31.0 \pm 30.0$ & $30.4 \pm 22.3$ & $p=0.667$ \\
\hline Day & $946 \pm 800$ & $960 \pm 486$ & $936 \pm 677$ & $p=0.667$ \\
\hline
\end{tabular}


Table 2: Intraocular pressure (IOP) and medication use assessment of patients before and after AGV implantation.

\begin{tabular}{|c|c|c|c|c|}
\hline & Total & NVG & Non-NVG & $p$ value \\
\hline \multicolumn{5}{|l|}{ IOP (mmHg) } \\
\hline Pre-AGV & $29.54 \pm 4.87$ & $28.36 \pm 4.76$ & $30.92 \pm 4.83$ & 0.193 \\
\hline Post-AGV $1^{\text {st }}$ month & $15.42 \pm 4.62$ & $16.00 \pm 6.00$ & $14.75 \pm 2.17$ & 0.742 \\
\hline Post-AGV $3^{\text {rd }}$ month & $16.19 \pm 4.65$ & $16.29 \pm 5.99$ & $16.08 \pm 2.61$ & 0.781 \\
\hline Post-AGV $6^{\text {th }}$ month & $13.92 \pm 3.03$ & $14.36 \pm 3.58$ & $13.42 \pm 2.27$ & 0.212 \\
\hline Post-AGV $12^{\text {th }}$ month & $12.88 \pm 4.17$ & $\begin{array}{l}14.33 \pm 4.11 \\
<0.001\end{array}$ & $\begin{array}{l}11.42 \pm 3.84 \\
<0.001\end{array}$ & 0.045 \\
\hline$p$ value & & & & \\
\hline \multicolumn{5}{|l|}{ Number of medication use } \\
\hline Pre-AGV & $3.62 \pm 0.85$ & $3.71 \pm 0.82$ & $3.50 \pm 0.90$ & 0.494 \\
\hline Post-AGV $12^{\text {th }}$ month & $1.00 \pm 1.23$ & $1.21 \pm 1.47$ & $0.75 \pm 0.86$ & 0.595 \\
\hline
\end{tabular}

Table 3: Best corrected visual acuity (BCVA) assessment of patients before and after AGV implantation. 


\begin{tabular}{|c|c|c|c|}
\hline & Total & NVG & Non-NVG \\
\hline \multicolumn{4}{|l|}{ Preoperative BCVA (before AGV) } \\
\hline Light perception & 0 & 0 & 0 \\
\hline Hand motion & $11(42.3 \%)$ & $8(57.1 \%)$ & $3(25.0 \%)$ \\
\hline$\leq 20 / 200$ - counting finger & $8(30.8 \%)$ & $6(42.9 \%)$ & $2(16.7 \%)$ \\
\hline$\geq 20 / 200$ & $7(26.9 \%)$ & 0 & $7(58.3 \%)$ \\
\hline \multicolumn{4}{|l|}{ BCVA (Post.AGV $3^{\text {rd }}$ month) } \\
\hline Loss of ligh perception & $1(3.8 \%)$ & $1(7.1 \%)$ & 0 \\
\hline Light perception & 0 & 0 & 0 \\
\hline Hand motion & $9(34.6 \%)$ & $6(42.9 \%)$ & $3(25 \%)$ \\
\hline$\leq 20 / 200$ - counting finger & $6(23.1 \%)$ & $5(35.7 \%)$ & $1(8.3 \%)$ \\
\hline$\geq 20 / 200$ & $10(38.5 \%)$ & $2(14.3 \%)$ & $8(66.7 \%)$ \\
\hline \multicolumn{4}{|l|}{ Change of BCVA (Post.AGV $3^{\text {rd }}$ month) } \\
\hline Improvement or maintenance & $21(80.8 \%)$ & $11(78.6 \%)$ & $10(83.3 \%)$ \\
\hline Decrease more than 1 line & $5(19.2 \%)$ & $3(21.4 \%)$ & $2(16.7 \%)$ \\
\hline \multicolumn{4}{|l|}{ BCVA (Post.AGV $6^{\text {th }}$ month) } \\
\hline Loss of ligh perception & $1(3.8 \%)$ & $1(7.1 \%)$ & 0 \\
\hline Light perception & 0 & 0 & 0 \\
\hline Hand motion & $8(30.8 \%)$ & $6(42.9 \%)$ & $2(16.7 \%)$ \\
\hline$\leq 20 / 200$ - counting finger & $6(23.1 \%)$ & $5(35.7 \%)$ & $1(8.3 \%)$ \\
\hline$\geq 20 / 200$ & $11(42.3 \%)$ & $2(14.3 \%)$ & $9(75 \%)$ \\
\hline \multicolumn{4}{|l|}{ Change of BCVA (Post.AGV $6^{\text {th }}$ month) } \\
\hline Improvement or maintenance & $25(92.6 \%)$ & $13(92.9 \%)$ & $12(100 \%)$ \\
\hline Decrease more than 1 line & $1(3.8 \%)$ & $1(7.1 \%)$ & 0 \\
\hline \multicolumn{4}{|l|}{ BCVA (Post.AGV $12^{\text {th }}$ month) } \\
\hline Loss of ligh perception & $2(8.3 \%)$ & $1(8.3 \%)$ & $1(8.3 \%)$ \\
\hline
\end{tabular}




\begin{tabular}{|llll|}
\hline Light perception & 0 & 0 & 0 \\
Hand motion & $6(25 \%)$ & $5(41.7 \%)$ & $1(8.3 \%)$ \\
$\leq 20 / 200$ - counting finger & $4(6.7 \%)$ & $3(25 \%)$ & $1(8.3 \%)$ \\
$\geq 20 / 200$ & $12(50 \%)$ & $3(25 \%)$ & $9(75 \%)$ \\
Change of BCVA (Post.AGV 12 ${ }^{\text {th }}$ month) & & & \\
Improvement or maintenance & $22(91.7 \%)$ & $11(91.7 \%)$ & $11(91.7 \%)$ \\
Decrease more than 1 line & $2(8.3 \%)$ & $1(8.3 \%)$ & $1(8.3 \%)$ \\
& & & \\
\hline
\end{tabular}

Table 4: Evaluation of surgical success and failure rates at 6 and 12 months.

\begin{tabular}{|clll|}
\hline & Total & NVG & Non-NVG \\
\hline $6^{\text {th }}$ month & & & \\
Complete success & $18 / 26(69.2 \%)$ & $11 / 14(78.6 \%)$ & $7 / 12(58.3 \%)$ \\
Qualified success & $25 / 26(96.2 \%)$ & $13 / 14(92.9 \%)$ & $12 / 12(100 \%)$ \\
Surgical failure & $1 / 26(3.8 \%)$ & $1 / 13(7.1 \%)$ & $0 / 12(0 \%)$ \\
& & & \\
\hline $12^{\text {th }}$ month & & & \\
Complete success & $15 / 24(62.5 \%)$ & $9 / 12(75 \%)$ & $6 / 12(50 \%)$ \\
Qualified success & $21 / 24(87.5 \%)$ & $10 / 12(83.3 \%)$ & $11 / 12(91.7 \%)$ \\
Surgical failure & $3 / 24(12.5 \%)$ & $2 / 12(16.7 \%)$ & $1 / 12(8.3 \%)$ \\
& & & \\
\hline
\end{tabular}

\section{Figures}




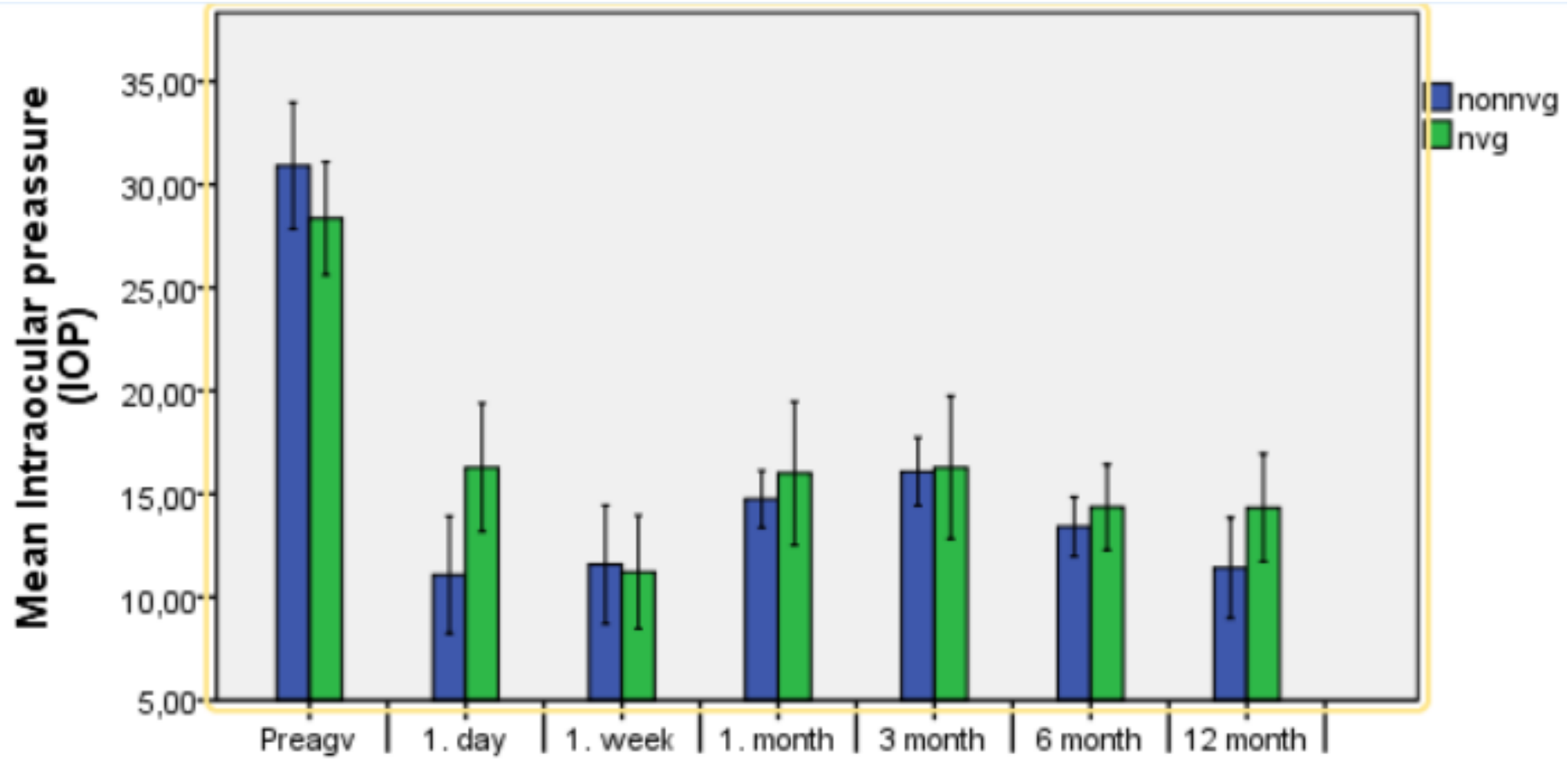

Figure 1

The mean intraocular pressure (IOP) distrubition of groups according to follow-up time. 


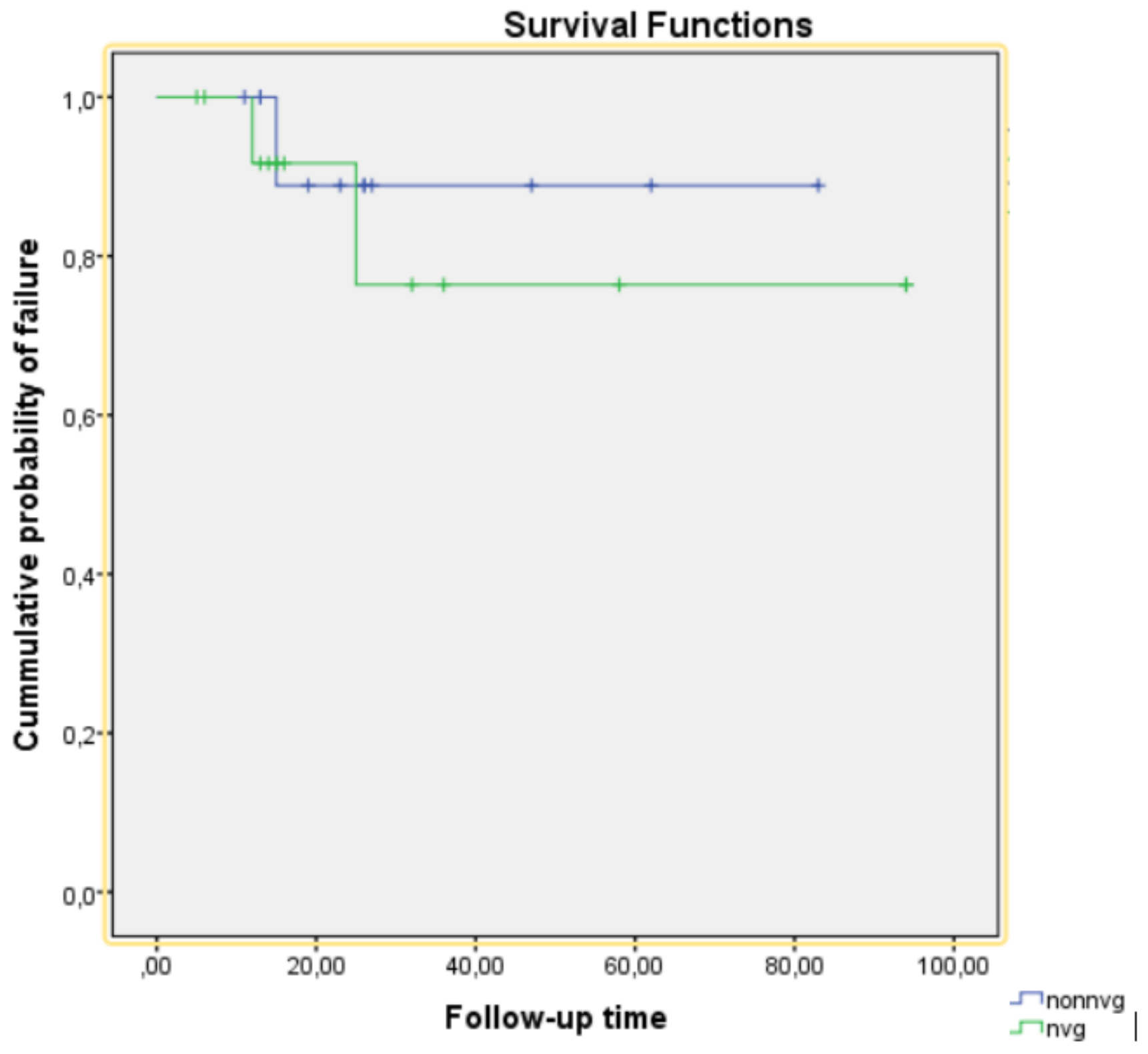

Figure 2

Cumulative probability of surgical failure. There was no significant difference in surgical failure rates of the NVG and non-NVG groups ( $P=0.581$; Kaplan-Meier survival analysis with the Mantel-Cox log rank test). 